\title{
Inflammation modulates expression of laminin in the central nervous system following ischemic injury
}

\author{
Kyungmin Ji and Stella E Tsirka*
}

\begin{abstract}
Background: Ischemic stroke induces neuronal death in the core of the infarct within a few hours and the secondary damage in the surrounding regions over a long period of time. Reduction of inflammation using pharmacological reagents has become a target of research for the treatment of stroke. Cyclooxygenase 2 (COX-2), a marker of inflammation, is induced during stroke and enhances inflammatory reactions through the release of enzymatic products, such as prostaglandin $(P G) E_{2}$.

Methods: Wild-type (WT) and COX-2 knockout (COX-2KO) mice were subjected to middle cerebral artery occlusion (MCAO). Additionally, brain slices derived from these mice or brain microvascular endothelial cells (BMECs) were exposed to oxygen-glucose deprivation (OGD) conditions. The expression levels of extracellular matrix (ECM) proteins were assessed and correlated with the state of inflammation.

Results: We found that components of the ECM, and specifically laminin, are transiently highly upregulated on endothelial cells after MCAO or OGD. This upregulation is not observed in COX-2KO mice or WT mice treated with COX-2 inhibitor, celecoxib, suggesting that COX-2 is associated with changes in the levels of laminins.

Conclusions: Taken together, we report that transient ECM remodeling takes place early after stroke and suggest that this increase in ECM protein expression may constitute an effort to revascularize and oxygenate the tissue.
\end{abstract}

Keywords: Extracellular matrix proteins, Inflammation, Ischemia, Laminin

\section{Background}

Cerebral ischemia results in neurological disability and constitutes the third leading cause of death in the US. It has devastating consequences as it results in death of neurons at the infarct core within a few hours after the blockade of blood flow to the brain [1]. Although re-establishment of blood flow using fibrinolytics is critical, inflammation that develops following the initial ischemic episode is a major mechanism by which cells in the penumbra degenerate [2], and therefore pharmacological strategies are formulated to limit this delayed phase of damage. Major mediators of inflammatory events are the members of the cyclooxygenase (COX) family. The two major COX isoforms are COX-1 and COX-2 and they catalyze the first step in the transformation of arachidonic acid to prostaglandins (PGs) and thromboxanes. In the

\footnotetext{
* Correspondence: stella@pharm.stonybrook.edu

Department of Pharmacology, Stony Brook University, Stony Brook, NY 11794-8651, USA
}

(c) $2012 \mathrm{Ji}$ and Tsirka; licensee BioMed Central Ltd. This is an Open Access article distributed under the terms of the Creative Commons Attribution License (http://creativecommons.org/licenses/by/2.0), which permits unrestricted use, distribution, and reproduction in any medium, provided the original work is properly cited. expressed constitutively on neurons, whereas $\mathrm{COX}-2$ is induced on microglia and astrocytes by inflammatory stimuli or injury $[3,4]$. COX-2 is considered a proinflammatory mediator leading to PG synthesis [5]. Prostaglandin $E_{2}\left(\mathrm{PGE}_{2}\right)$ induces fever and pain, increases vascular permeability and recruit inflammatory cells to injury sites [6]. However, evidence suggests that COX-2 is also involved in inflammation reduction/resolution $[7,8]$. The COX-2 inhibitors NS398 and indomethacin have differential effects depending on their administration time: early administration during a pleurisy model suppressed inflammation, but late administration exacerbated inflammation through $\mathrm{PGE}_{2}$ and 15-deoxy- $\delta 12,14$-prostaglandin $\mathrm{I}_{2}\left(15 \mathrm{~d}-\mathrm{PGJ}_{2}\right)$ [7]. In a different paradigm, $\mathrm{PGE}_{2}$ reduced proinflammatory mediators release from mast cells and inflammatory cells recruitment in lungs [9], suppressed inducible nitric oxide synthase (iNOS) and tumor necrosis factor (TNF) $\alpha$, but enhanced interleukin 10 and 
interleukin 13 expression in LPS-stimulated microglia $[10,11]$. COX-2 also oxygenates anti-inflammatory endocannaboids [12] that protect against ischemic death [13]. These studies suggest that COX-2 can drive or resolve inflammation; therefore, careful regulation of COX-2 may be important for reducing inflammation-mediated neurodegeneration $[14,15]$.

The extracellular matrix (ECM) of the CNS is essential for maintenance of brain homeostasis. Although its exact composition is not defined, it is thought that hyaluronan, tenascin- $\mathrm{C}$, and proteoglycans are present in brain parenchyma [16], and fibronectin (FN) and laminin in the brain vasculature $[17,18]$. Proteoglycans such as aggrecan, versican, and brevican constitute perineuronal nets majorly $[19,20]$, and tenascin is involved in regulation or promotion of neurite outgrowth [21-23]. Moreover, the structure of these molecules is changed in response to brain injury such as stroke [24,25]. The ECM and secreted neurotrophic or other factors, such as vascular endothelial growth factor (VEGF) or brainderived neurotropic factor (BDNF), are involved in neuronal reorganization and recovery in $\mathrm{MCAO}$ brains [24,26-31]. Among the ECM proteins, laminin is rich primarily in the basement membranes of the endothelial cells of the blood-brain barrier (BBB) [32]. Laminin levels have been reported to increase or decrease during CNS injury [29,33]. Laminins are present in 16 isoforms that are composed of $\alpha, \beta$ and $\gamma$ polypeptides. Different laminin isoforms have unique distribution, and are temporally and spatially regulated [34]. Several of the laminin subunits have been shown to be expressed in the rodent brain, including $\alpha 1$ to $5, \beta 1$, and $\gamma 1[35,36]$, and the $\beta 3$ and $\gamma 1$ chains have been reported in sprouting neurons and rat astrocytes [37,38]. Laminin $\alpha 2$ is localized in the basal lamina of cerebral blood vessels, and may be important for the selective filtration capability of BBB [39]. The expression of laminin is upregulated in endothelial cells and astrocytes within $24 \mathrm{~h}$ following ischemia and stab wounds $[40,41]$.

The work described here investigated whether COX-2 can modulate ECM changes induced by ischemic injury. We focused on laminin as one abundant component of the ECM. Our results indicate that laminin levels on blood vessels are regulated by COX-2 following permanent or transient ischemia. Understanding the functional outcome and timing of laminin expression regulation by COX-2 in the progression of ischemia-induced neuronal damage could suggest a basis for potentially rationalizing drug specific interference with ischemia.

\section{Methods}

\section{Animals and in vivo experiments}

All animal procedures were approved by the Stony Brook University Institutional Animal Care and Use Committee
(IACUC). Adult wild-type (C57BL6; WT) mice were obtained from Jackson Laboratory (Bar Harbor, ME, USA). Cyclooxygenase knockout mice (COX-2KO in the C57Bl6 background) were provided by Dr SK Dey (Cincinnati Children's Hospital). Mice were bred in house at Stony Brook. For middle cerebral artery occlusion (MCAO), mice were anesthetized and underwent permanent MCAO (pMCAO) using a heat-blunted, small 6-0 siliconized monofilament (Ethicon, Somerville, NJ, USA). A fiberoptic probe was glued to the parietal bone $(2 \mathrm{~mm}$ posterior and $5 \mathrm{~mm}$ lateral to bregma) and connected to a laser-Doppler flowmeter (Periflux System 5010, Perimed, Stockholm, Sweden) for continuous monitoring of cerebral blood flow in the ischemic territory center. Celecoxib (Biovision, Milpitas, CA, USA) was given at $5 \mathrm{mg} / \mathrm{kg}$ intraperitoneally (in $50 \%$ dimethylsulfoxide (DMSO)) 30 minutes before the injury. The animals were killed at different times. The infarct area was visualized by cresyl violet and 2,3,5-triphenyltetrazolium chloride (TTC) staining.

\section{Tissue preparation}

Mice were anesthetized after surgery and perfused with saline solution, followed by $4 \%$ paraformaldehyde (PFA) in $0.1 \mathrm{M}$ phosphate buffer, $\mathrm{pH}$ 7.2, for tissue fixation. Brains were obtained and post fixed overnight at $4{ }^{\circ} \mathrm{C}$ in $4 \%$ PFA. Fixed brains were stored at $4{ }^{\circ} \mathrm{C}$ in $30 \%$ sucrose solution until they sank. Six separate series of $20 \mu \mathrm{m}$ coronal brain sections were obtained with a cryostat. For protein preparation, mice were anesthetized and perfused with saline. Brains were sliced with Mice Brain Slicer Matrix (ASI Instruments, Warren, MI, USA) and a razor blade. The slice including the ipsilateral sides (ischemic lesion) was selected, and tissue blocks $\left(1.0 \times 1.0 \times 1.0 \mathrm{~mm}^{3}\right)$ in the lesion of ipsilateral sides and in the same area of contralateral (not ischemic) sides were collected, and stored at $-70{ }^{\circ} \mathrm{C}$ until use.

\section{Measurement of Infarct volume}

To quantify the infarct volume TTC staining was used: mice were killed and perfused with saline after MCAO. The brain slices, obtained as described above, $(2 \mathrm{~mm})$ were incubated for 15 minutes in $2 \%$ TTC (SigmaAldrich, St. Louis, MO, USA) at $37{ }^{\circ} \mathrm{C}$, and fixed in $4 \%$ PFA at $4{ }^{\circ} \mathrm{C}$. TTC stains viable brain tissue dark red, whereas infarcted tissue areas remain unstained (white). To measure the TTC-negative area, serial sections from each animal were viewed in a Nikon E600 microscope, photographed and the area measured using NISElements software (ImageJ). The infarct volume was calculated as sum of (area $\times$ section thickness) for each animal.

\section{Oxygen-glucose deprivation (OGD)}

Immortalized human brain microvascular endothelial cells (BMECs) were a gift from Dr M Stins at Johns 
Hopkins University, School of Medicine [42]. BMECs were cultured in RPMI1640 medium, supplemented with $10 \%$ NuSerum, $10 \%$ fetal bovine serum (FBS), minimal essential medium (MEM) vitamins, MEM non-essential amino acids, $1 \mathrm{mM}$ sodium pyruvate, $2 \mathrm{mM}$ D-glutamine, $30 \mu \mathrm{g} / \mathrm{ml}$ endothelial growth supplement, $5 \mathrm{U} / \mathrm{ml}$ heparin, and penicillin/streptomycin at $37{ }^{\circ} \mathrm{C}$ in $5 \% \mathrm{CO}_{2}$. The cells form a monolayer connected via tight junctions that can form and model an in vitro blood-brain barrier [43]. For in vitro ischemia, the cells were maintained in glucose-free and serum-free (OGD conditioned) medium under $1 \% \mathrm{O}_{2} / 5 \% \mathrm{CO}_{2}$ at $37{ }^{\circ} \mathrm{C}$ (Oxycycler C4, Biospherix, Redfield, NY, USA) for 3 days. Afterwards, the cells were removed from the hypoxic chamber and replaced with pre-OGD conditioned medium in a humidified aerobic incubator at $37{ }^{\circ} \mathrm{C}$ for $4 \mathrm{~h}$ recovery [44].

\section{Immunoblotting, immunohistochemistry, and immunofluorescence}

For immunoblotting, cells or tissue from the ipsilateral or contralateral hemisphere were lysed in $50 \mathrm{mM}$ Tris$\mathrm{HCl}(\mathrm{pH} 7.4)$ containing $1 \%$ Nonidet P-40, $0.25 \% \mathrm{Na}-$ deoxycholate, $150 \mathrm{mM} \mathrm{NaCl}$, and protease inhibitors cocktail (Sigma-Aldrich) using a homogenizer on ice, incubated for 30 minutes, and centrifuged. The extracts were run on a reducing $10 \%$ sodium dodecylsulfate polyacrylamide gel electrophoresis (SDS-PAGE) and transferred to polyvinylidene fluoride (PVDF) membrane (Immobilon-P; Millipore, Billerica, MA, USA). The blots were incubated using primary antibodies (Table 1) overnight at $4{ }^{\circ} \mathrm{C}$; followed by incubation with horseradish peroxidase-labeled secondary antibody (Invitrogen, Carlsbad, CA, USA) for $1 \mathrm{~h}$ at room temperature, and enhanced chemiluminescence (ECL) (Pierce Chemical Co., Rockford, IL, USA). After stripping, the membranes were reblotted with mouse anti- $\alpha$-tubulin (Upstate Biotechnology, Lake Placid, NY, USA) antibody. Expression levels were quantified using the ImageJ software, normalized against $\alpha$-tubulin. For immunohistochemistry and immunofluorescence, sections were fixed in $4 \%$ PFA in phosphate-buffered saline (PBS) for 30 minutes. After washing in PBS, they were blocked in $0.2 \%$ Triton X-100 and $1 \%$ bovine serum albumin (BSA) in PBS. The primary antibodies used were listed in Table 1 . The sections were incubated with primary antibody in $0.2 \%$ Triton X-100 and $1 \%$ BSA in PBS at $4{ }^{\circ} \mathrm{C}$ overnight. After rinsing in PBS, the sections were incubated with biotinylated secondary antibodies, the avidin/biotin system, and visualized using 3,3'-diaminobenzidine, or Alexa Fluor488-conjugated or Alexa Fluor555-conjugated secondary antibodies (Invitrogen) for $1 \mathrm{~h}$. The sections were rinsed in PBS, coverslipped, and examined using confocal microscopy or epifluorescence microscopy.

\section{Reverse transcription polymerase chain reaction (RT-PCR)}

Total RNA was extracted using TRIzol (Invitrogen) and cDNA was prepared using reverse transcriptase, according to manufacturer's instructions (Invitrogen). The PCR primers used are listed in Table 2. PCR products were separated by electrophoresis in $1 \%$ agarose gels and detected under ultraviolet (UV) light.

Table 1 Antibodies used for immunostaining or immunoblotting

\begin{tabular}{|c|c|c|c|c|c|}
\hline Antigen & Antibody & Dilution & Source & Catalog no. & Method \\
\hline NeuN & Mouse monoclonal & $1: 1,000$ & Chemicon & MAB377 & $\mathrm{IHC}$ \\
\hline Iba-1 & Rabbit polyclonal & $1: 1,000$ & Wako & 019-19741 & $\mathrm{HCC}$ \\
\hline TLR9 & Rabbit polyclonal & $1: 500$ & Imgenex & IMG431 & WB \\
\hline CD14 & Goat polyclonal & $1: 1,000$ & Santa Cruz Biotechnology & sc-6999 & WB \\
\hline Fibrin & Mouse monoclonal & $1: 200$ & A gift of Dr Galanakis & {$[45]$} & WB \\
\hline Collagen IV & Rabbit polyclonal & $1: 500$ & Chemicon & AB756 & WB \\
\hline \multirow[t]{2}{*}{ Pan-laminin } & Rabbit polyclonal & $1: 1,000$ & Sigma-Aldrich & L9393 & $\mathrm{HC}$ \\
\hline & & $1: 5,000$ & & & WB \\
\hline a-Tubulin & Mouse monoclonal & $1: 7,000$ & Upstate Biotechnology & $05-829$ & WB \\
\hline Occludin & Mouse monoclonal & $1: 250$ & Zymed & $33-1500$ & $\mathrm{IHC}$ \\
\hline HIF-1a & Rabbit polyclonal & $1: 1,000$ & Bethyl Laboratories & A300-286A & WB \\
\hline $\operatorname{cox}-2$ & Mouse monoclonal & $1: 500$ & BD Biosciences & 610203 & WB \\
\hline Mac-2 & Rat monoclonal & $1: 1,000$ & Cedarlane & CL8942AP & WB \\
\hline CD45 & Rat monoclonal & $1: 500$ & BD Biosciences & 553076 & $\mathrm{HHC}$ \\
\hline VEGF & Rabbit polyclonal & $1: 200$ & Thermo scientific & RB-9031 & WB \\
\hline GFAP & Rabbit polyclonal & $1: 1,000$ & DAKO & Z0334 & $\mathrm{IHC}$ \\
\hline
\end{tabular}

COX-2, cyclooxygenase 2; GFAP, glial fibrillary acidic protein; HIF-1a, hypoxia-inducible factor 1a; Iba-1, ionized calcium binding adaptor molecule 1; IHC, immunohistochemisty; TLR9, Toll-like receptor 9; VEGF, vascular endothelial growth factor; WB, western blot. 


\begin{tabular}{|c|c|c|}
\hline Gene & Forward/reverse & Sequences $\left(5^{\prime}-3^{\prime}\right)$ \\
\hline \multirow[t]{2}{*}{ Laminin a2 } & $\mathrm{F}$ & GCCGCACTCCTGGACCAACC \\
\hline & $\mathrm{R}$ & TGCCAGTGCTCGCAGCCATC \\
\hline \multirow[t]{2}{*}{ Laminin a4 } & $\mathrm{F}$ & ATCGAGGGGAGCGCAGTGGT \\
\hline & $\mathrm{R}$ & GCAGAACCGGGGTGTGCCTC \\
\hline \multirow[t]{2}{*}{ Laminin a5 } & $\mathrm{F}$ & CTGTGGAGCCCGCCTGTGTG \\
\hline & $\mathrm{R}$ & CCCCACGCGACACTGGTCAC \\
\hline \multirow[t]{2}{*}{ Laminin $\beta 1$} & $\mathrm{~F}$ & CGAACCTGCAGCGAGTGCCA \\
\hline & $\mathrm{R}$ & GTTCCGCTGCTGGGCTCTGG \\
\hline \multirow[t]{2}{*}{ Laminin $\beta 3$} & $\mathrm{~F}$ & CCAGCGCACACGGCTTCTCA \\
\hline & $\mathrm{R}$ & GTGCCCTGCCGAAGGTTCCC \\
\hline \multirow[t]{2}{*}{ Laminin $\gamma 1$} & $\mathrm{~F}$ & CTGTGAGACTGTGCCGCCCG \\
\hline & $\mathrm{R}$ & ACAGTGCTGGCCGGTGATGC \\
\hline \multirow[t]{2}{*}{ Laminin $\gamma 2$} & $\mathrm{~F}$ & CGGCTGTGTGTAGCGGGGTG \\
\hline & $\mathrm{R}$ & CAGCAGGAGCGCGACACCAA \\
\hline \multirow[t]{2}{*}{ actin } & $\mathrm{F}$ & GCTCGTCGTCGACAACGGCT \\
\hline & $\mathrm{R}$ & CAAACATGATCTGGGTCATCTTCTC \\
\hline
\end{tabular}

Using permanent MCAO we followed the effect of ischemia and local inflammation, and using transient MCAO we followed the effect of systemic inflammatory cell infiltration on changes in ECM proteins during post-injury CNS reorganization.

\section{Statistics}

Statistical significance was assessed by analysis of variance (ANOVA), followed by Student-Newman-Keuls multiple comparison tests. All analyses were performed using SPSS, V.8.0 (SPSS, Chicago, IL, USA). Values are means \pm SEMs of at least three independent experiments using at least five animals per experimental procedure and mouse strain, unless otherwise indicated.

\section{Results}

Laminin expression is transiently upregulated in wild-type, but not COX-2KO, mice after MCAO

We used permanent MCAO (pMCAO) to investigate how ischemia-induced local inflammatory events affect the ECM. The extent of neuronal death and local inflammation (microglial cell activation) were assessed over time. The number of Nissl bodies was reduced at $3 \mathrm{~h}$ compared to that in contralateral sides following pMCAO (Figure 1A,B and Additional file 1: Figure S1) and the infarct volume was increased (Figure 1E). Regions not stained with TTC indicating cerebral infarction were observed within $6 \mathrm{~h}$ following pMCAO (Figure 1C). The state of microglial activation was also visualized using the Iba-1 marker, which is specific for macrophages/microglia (Figure 1D). Change of microglial morphology to an ameboid state was observed using Iba1 staining within 1 to $3 \mathrm{~h}$ after pMCAO, and sustained until at least $48 \mathrm{~h}$ after the injury. Similarly, the infiltration of leukocytes was assessed after MCAO (Additional file 1: Figure S1): immunoreactivity for CD45 was evident $1 \mathrm{~h}$ after MCAO, as well as at later timepoints, namely at 24 and $48 \mathrm{~h}$.

As COX-2 is one of the critical contributors to microglial activation [4], we assessed the extent of neuronal death and other parameters in $\mathrm{COX}-2^{-/-}$mice (COX$2 \mathrm{KO}$ ) relative to wild-type (WT) animals. COX-2KO mice were subjected to MCAO alongside WT animals. At $12 \mathrm{~h}$ after injury the extent of neurodegeneration in COX-2KO mice was decreased compared to WT mice (Figure 2A, upper and infarct volume graph), as reported previously [46]. Microglial activation was similarly reduced (data not shown). When we evaluated the expression of common ECM components, we found that proteins such as laminin, fibrinogen, fibronectin (not shown), and collagen IV were upregulated in ischemic brain (Figure 2B,C). The markers tested exhibited a transient increase after MCAO in WT animals. This transient increase was not detectable in the sham and contralateral (not ischemic) side, marked in Figure 2B, $\mathrm{C}$ as $\mathrm{C} 12$ (contralateral side $12 \mathrm{~h}$ post MCAO). In COX$2 \mathrm{KO}$ tissue extracts, the transient increase was not observed at the time points examined. This result suggests that the MCAO injury probably induces and COX2 could be involved in an inflammation-mediated change in the ECM protein expression.

Since laminin was the ECM protein whose levels were predominantly affected by MCAO, and given the known involvement of laminin in revascularization, we examined whether the MCAO and ECM changes also involved changes in the expression of VEGF, a factor known for mediating angiogenesis and neoangiogenesis. As shown in Additional file 2: Figure S2, the levels of VEGF were elevated in wild-type animals at 6 and $12 \mathrm{~h}$ post MCAO (peak at $6 \mathrm{~h}$ ), but this increase was drastically attenuated in $\mathrm{COX}-2 \mathrm{KO}$ mice, suggesting that $\mathrm{COX}-2$ could be involved in laminin-mediated angiogenesis [47].

\section{Laminin is increased in endothelial cells after ischemic injury}

Among the ECM markers investigated, the most prominent change in protein levels was observed in laminin, as shown in Figure 2C. In the subsequent experiments we focused our investigation on laminin and its expression after stroke. To ascertain the cellular localization of laminin, we used occludin as an indicator of endothelial cells on the blood vessels since laminin has been considered as a major component of the ECM of the BBB [17]. Laminin expression was prevalent on occludin $^{+}$cells (Figure 3A), demonstrating that endothelial cells were one cellular source of upregulated laminin [36,48]. To further confirm that laminin expression was increased 


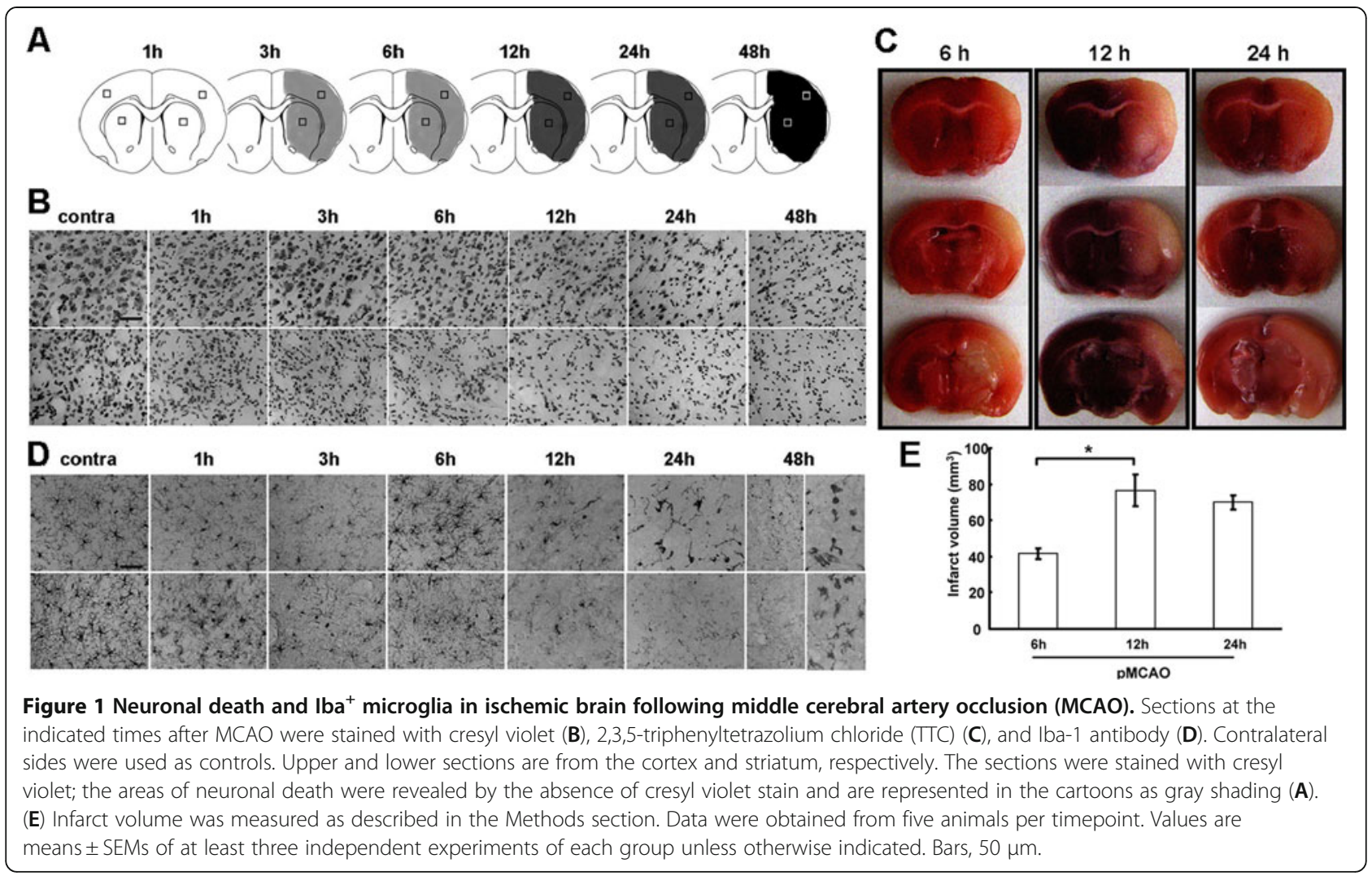

on endothelial cells, brain microvascular endothelial cells (BMECs) were subjected to conditions of OGD, as described in the Methods section, and analyzed by immunoblotting. Laminin expression, in particular $\beta$ and $\gamma$ subunits, was upregulated on endothelial cells following injury (Figure 3B).

The antibody used in Figures $2 \mathrm{C}$ and $3 \mathrm{~A}, \mathrm{~B}$ was a panlaminin antibody, so we sought to determine which laminin subunits are upregulated after MCAO. We used semiquantitative RT-PCR for each laminin subunit in extracts from the ipsilateral side of MCAO animals at the indicated times (Figure $3 \mathrm{C}$ ). The analysis showed that laminins $\alpha 2, \beta 3$, and $\gamma 1$ were upregulated within $24 \mathrm{~h}$ (Figure 3C).

\section{Pharmacological inhibitors of COX-2 modulate laminin levels after MCAO}

COX-2 deficiency modulated the levels of several ECM markers following MCAO (Figure 2B,C). Focusing again on laminin, we assessed whether this effect of COX-2 was acute or rather a potential developmental effect. To address this concern, we impaired COX-2 activity pharmacologically using celecoxib (coxib). We used first OGD in culture, as described above. Coxib was given at 2.5 and $5 \mu \mathrm{M}$ during the OGD and the levels of laminin were examined using immunoblotting. As shown in Figure 4A,B, the OGD samples had higher levels of laminin compared to control samples. When coxib was used, the levels of laminin were decreased down to control levels. Similar to laminin, the hypoxia inducible factor $1 \alpha$ (HIF-1 $\alpha)$, which a classic marker upregulated during ischemia or OGD [49], was decreased in the presence of coxib. The levels of $\alpha$-tubulin or COX-2 remained the same in all conditions. Coxib was also administered in vivo to wild-type mice immediately before MCAO. More intact Nissl bodies were observed in coxib-treated mice (WT + coxib) compared to control ones that had not been treated with coxib (WT + vehicle) (Figure $4 \mathrm{C}$ ). In these $\mathrm{Nissl}^{-}$area, laminin expression was dramatically decreased in coxib-treated mice (+coxib) compared to control mice (vehicle) (Figure 4C,D) and was reminiscent of laminin expression levels in COX$2 \mathrm{KO}$ mice. Notably, the intense staining indicating increased expression of blood vessels (endothelial cells) was not observed in the coxib-treated animal tissues. These results suggest that COX-2 can regulate acutely laminin expression.

\section{COX-2 acts through E-prostanoid 3 (EP3) receptors to modulate ECM protein expression}

We assessed whether the effect of COX-2 on laminin and ECM protein expression was mediated through prostaglandins and prostaglandin receptors. We used pharmacological inhibitors of EP receptors on BMECs 


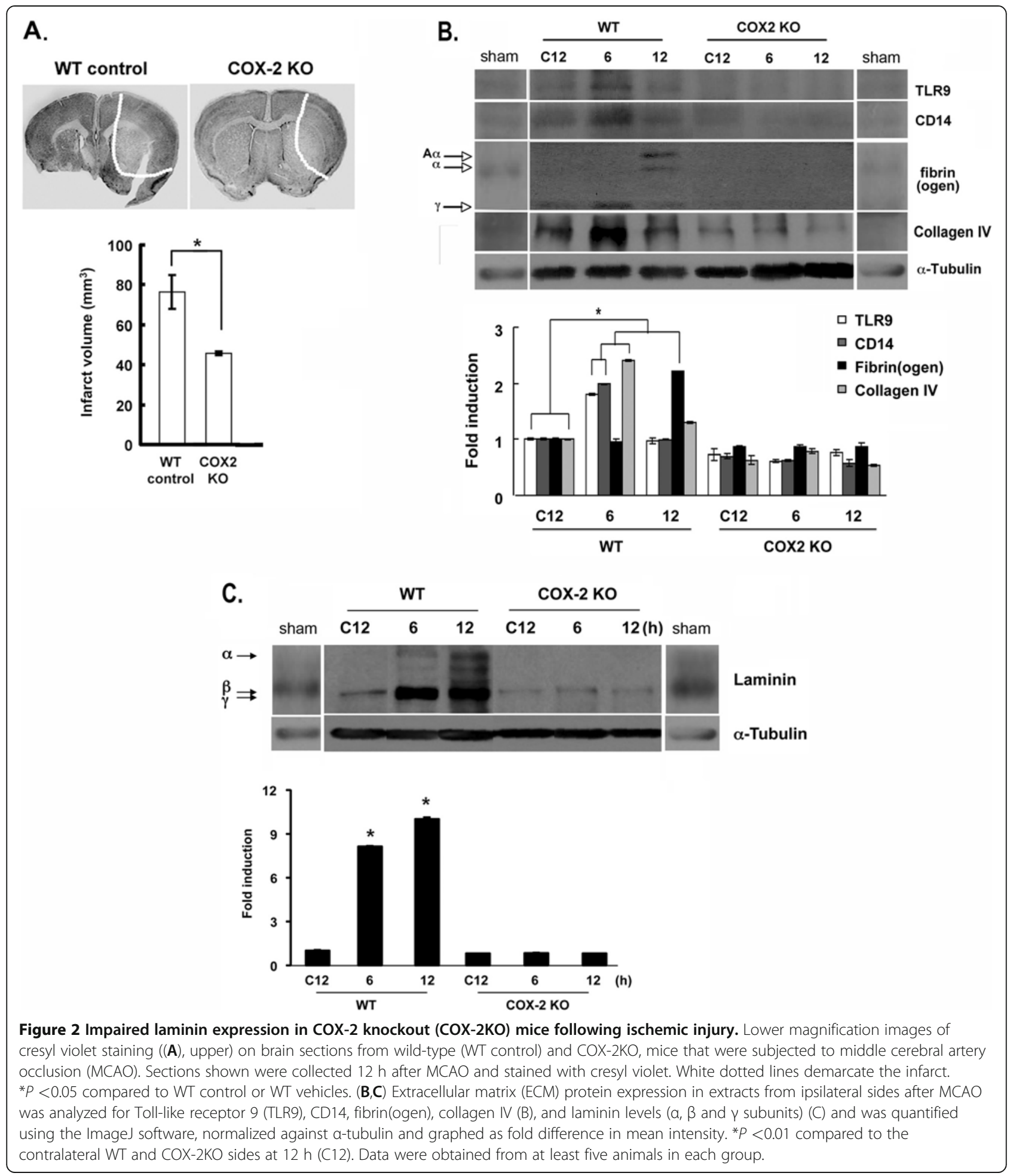

and subjected them to OGD. Of the antagonists used, SC51089 (EP1), AH6809 (EP2), L798,106 (EP3) and AH23848 (EP4), only the EP3 antagonist decreased laminin levels (Figure 5A). The combination of coxib and L798,106 did not result in further laminin decrease expression (Figure 5B). This result suggests that COX-2 regulates laminin expression via EP3 receptor activation, which mainly function to inhibit adenylyl cyclase via $\mathrm{Gi}$ activation [50].

As discussed earlier, in Figure 2, other ECM protein components were also increased after MCAO, and their expression correlated with increased inflammation. We 


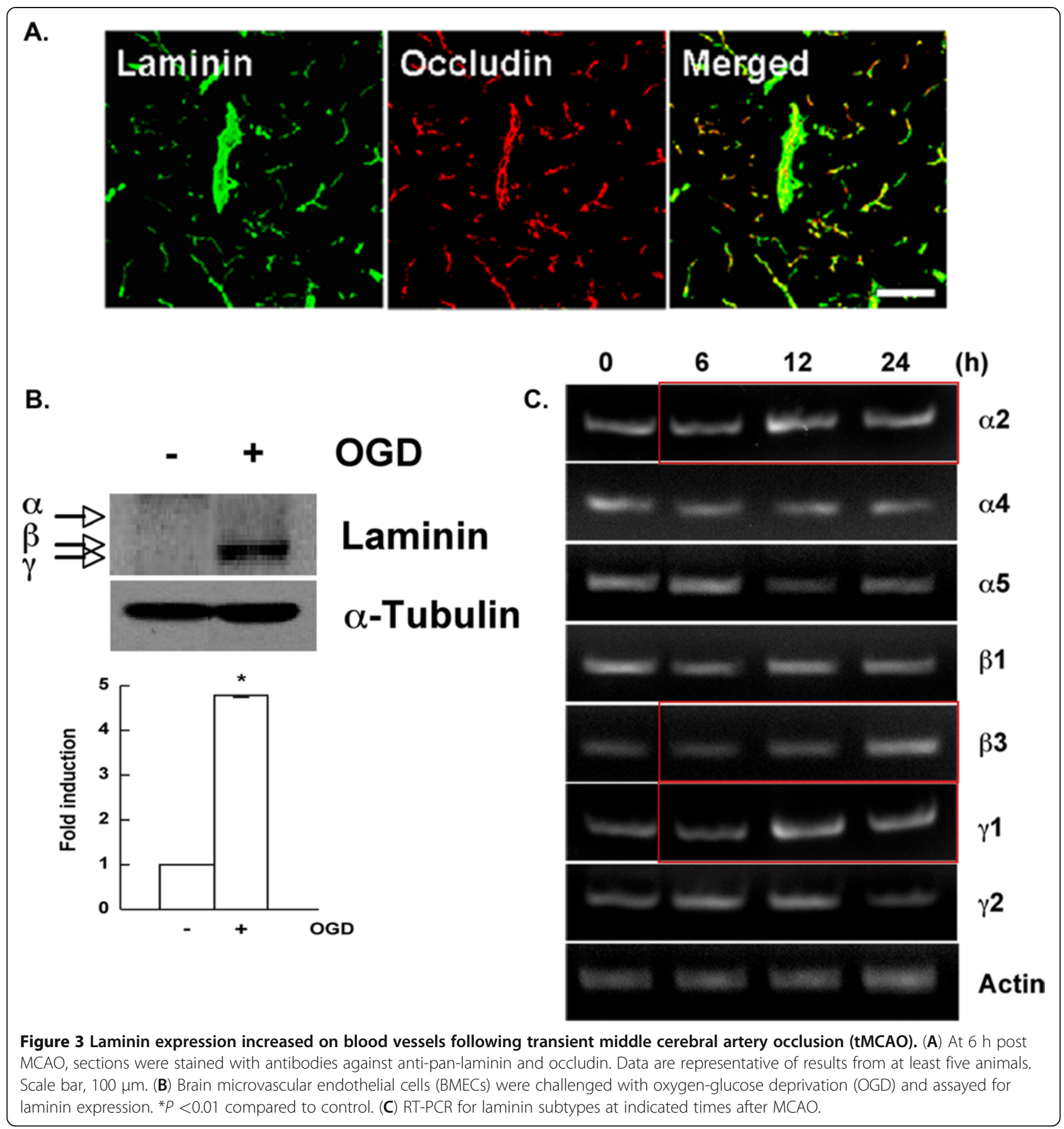

evaluated the expression of markers not directly associated with the COX-2 pathway (TLR9, Mac-2, CD14) in the presence of coxib or EP antagonists, and found that their expression was also decreased when the COX-2 pathway was inhibited (Figure $5 \mathrm{C}$ ). These results suggested that laminin and other ECM protein expression increase is associated with brain inflammation.

Because the EP3 inhibitor inhibited the induction of laminin (Figure 5A), we explored whether incubation of BMECs with $\mathrm{PGE}_{2}$ would result in increase of laminin expression. The cells were treated with increasing concentrations of $\mathrm{PGE}_{2}$ over a period of 2 days. As shown in Figure 6, a strong upregulation of all laminin subunits was evident at the 1-day but mostly at the 2-day timepoint. This result further supports the involvement of COX-2 $/ \mathrm{PGE}_{2}$ in the processes that lead to laminin induction.

\section{Discussion}

ECM components play regulatory roles in various cellular events [51-53], including healing/repair processes 


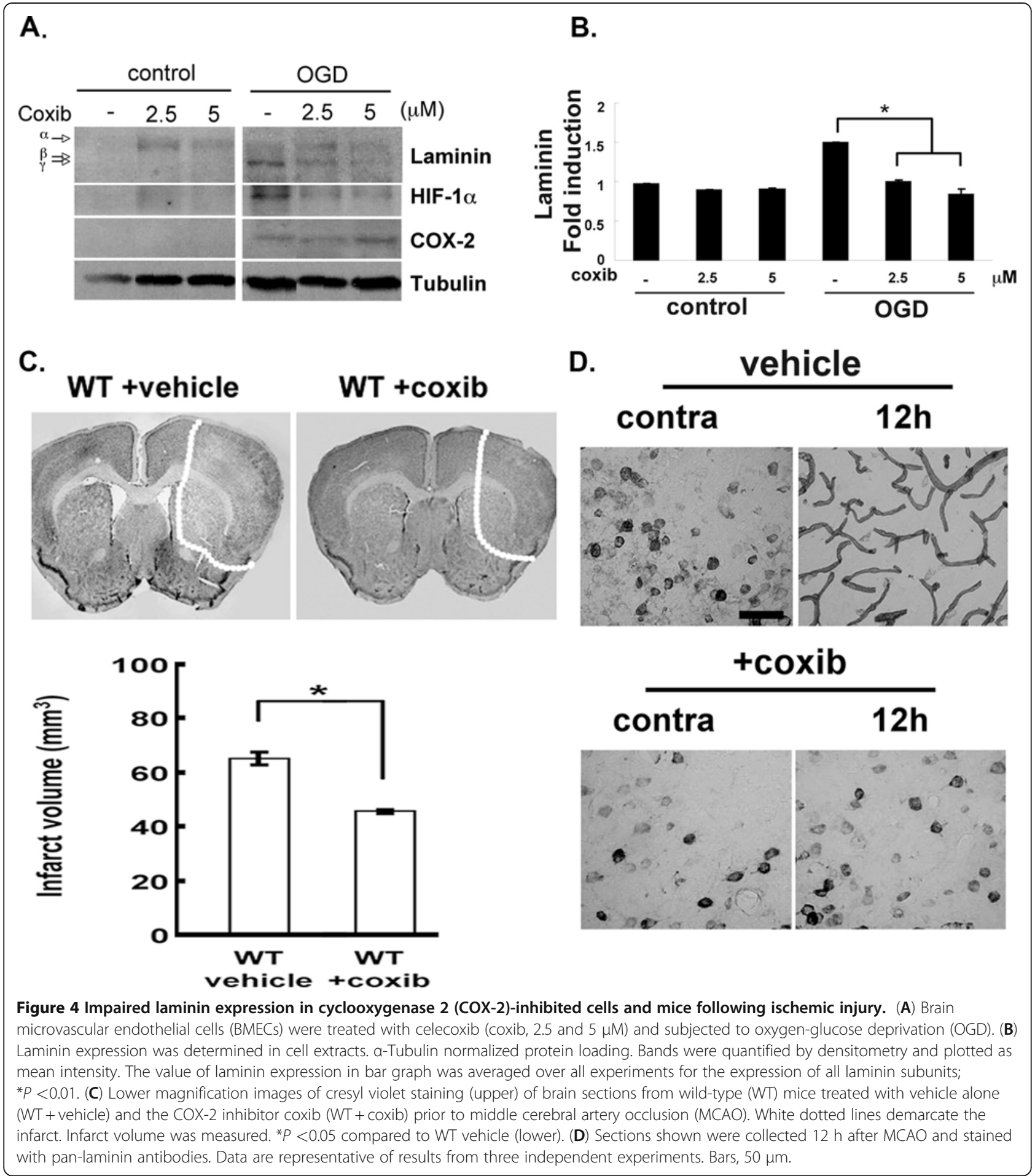

after injury [54]. For some ECM proteins it has been reported that their expression increases in ischemia and stab wounds $[40,41]$, but it is not known what its contribution to the injury outcome is. Focusing on one ECM component, we report that the increase in laminin depends on COX-2 activity.
Laminin upregulation has been linked to wound healing stimulation [54,55] and angiogenesis. In a skin wound model, application of laminin peptides increased the wound coverage and repair and was accompanied by enhanced angiogenesis. Laminins $\alpha 2, \beta 3$, and $\gamma 1$ are increased in brain following transient ischemic injury. 


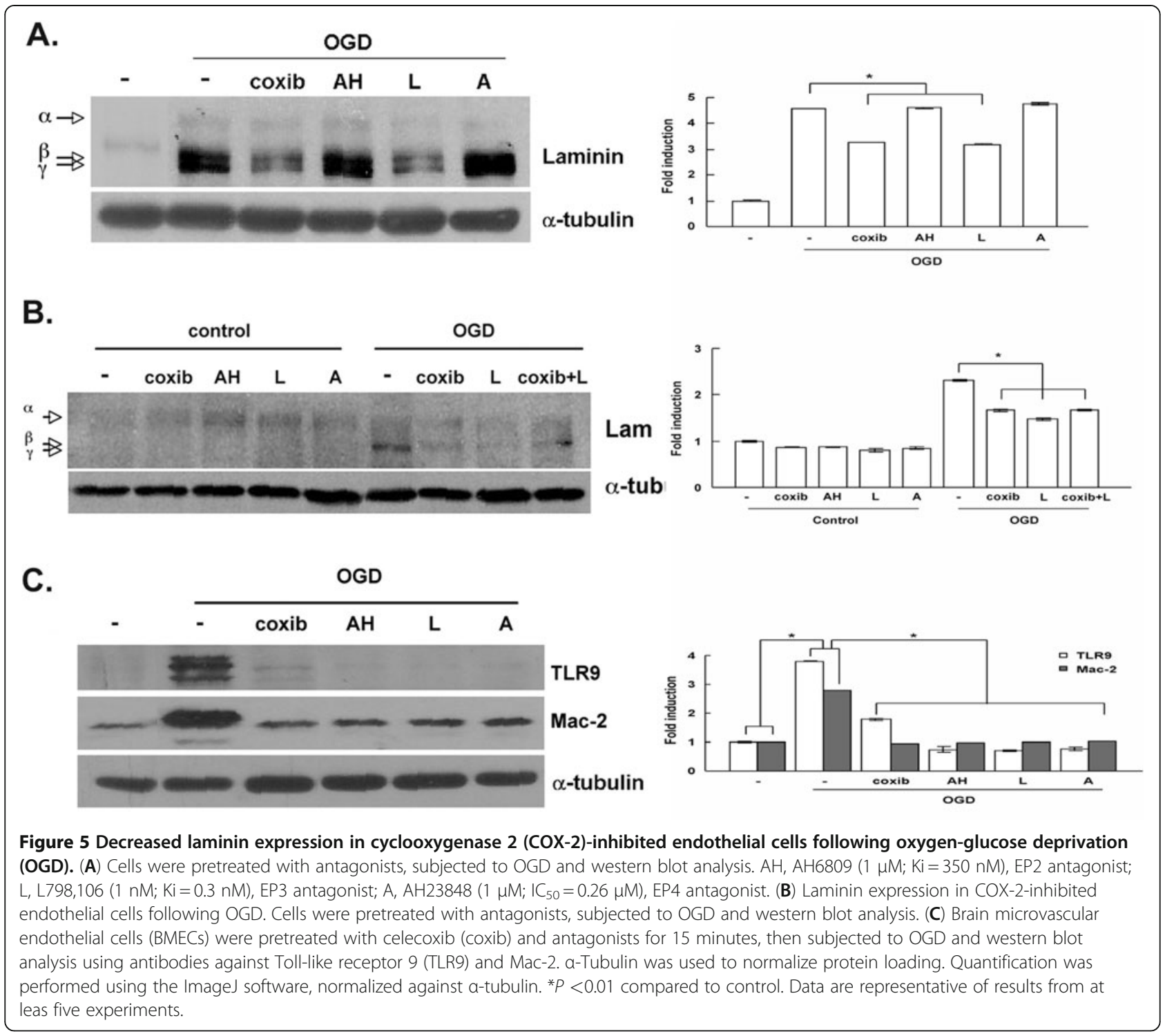

These laminins have been reported to be expressed in brain $[33,38,56]$. The biological roles of laminin subtypes and trimer molecules are largely unknown, thus, information about their functions derives from the phenotype of deficient or knockout mice. Laminin $\alpha 1$ is involved in epiblast differentiation [34]. Laminin $\alpha 2$ is expressed in basal lamina surrounding neurons and muscle [57]. $\alpha 2$ deficiency causes congenital muscular dystrophy [58]. Laminin $\beta 1$ deficient mice lack basement membranes and display defects in the neuromuscular synapse [34]. Laminin $\beta 3$ is expressed on the basal lamina and ECM of all cerebral microvessels [59]. The $\gamma 1$ subunit is rapidly degraded during excitotoxicity [60] or ethanolinduced neurodegeneration [61]. Although these subunits were upregulated after MCAO, it is not clear if they form a single laminin isoform or distinct heterotrimers.
Moreover, it is not clear if they would act through the same receptors, integrins, dystroglycan or syndecan [34].

COX-2 activity enhances the production of VEGF [47], which in turn stimulates angiogenesis. The downstream effectors of COX-2 would be different prostaglandins such as $\mathrm{PGI}_{2}, \mathrm{PGD}_{2}, \mathrm{PGE}_{2}, \mathrm{PGF}_{2 \alpha}$, and thromboxane (Tx). These prostaglandins bind to the receptor with the greatest affinity: I prostanoid (IP) receptor binds $\mathrm{PGI}_{2}$, DP binds PGD2, EP binds $\mathrm{PGE}_{2}$, FP binds $\mathrm{PGF}_{2 \alpha}$, and TP binds $\mathrm{TxA}_{2}$, and they are basically $\mathrm{G}$ protein-coupled prostanoid receptors (GPCR) $[62,63]$. Among the prostaglandins, prostaglandin $\mathrm{E}_{2}\left(\mathrm{PGE}_{2}\right)$ is the most widely produced prostaglandin in the body, and considered to participate in inflammation associated with redness, swelling and pain $[64,65]$ and has significant effects on proliferation, the apoptosis of lymphocytes and the 


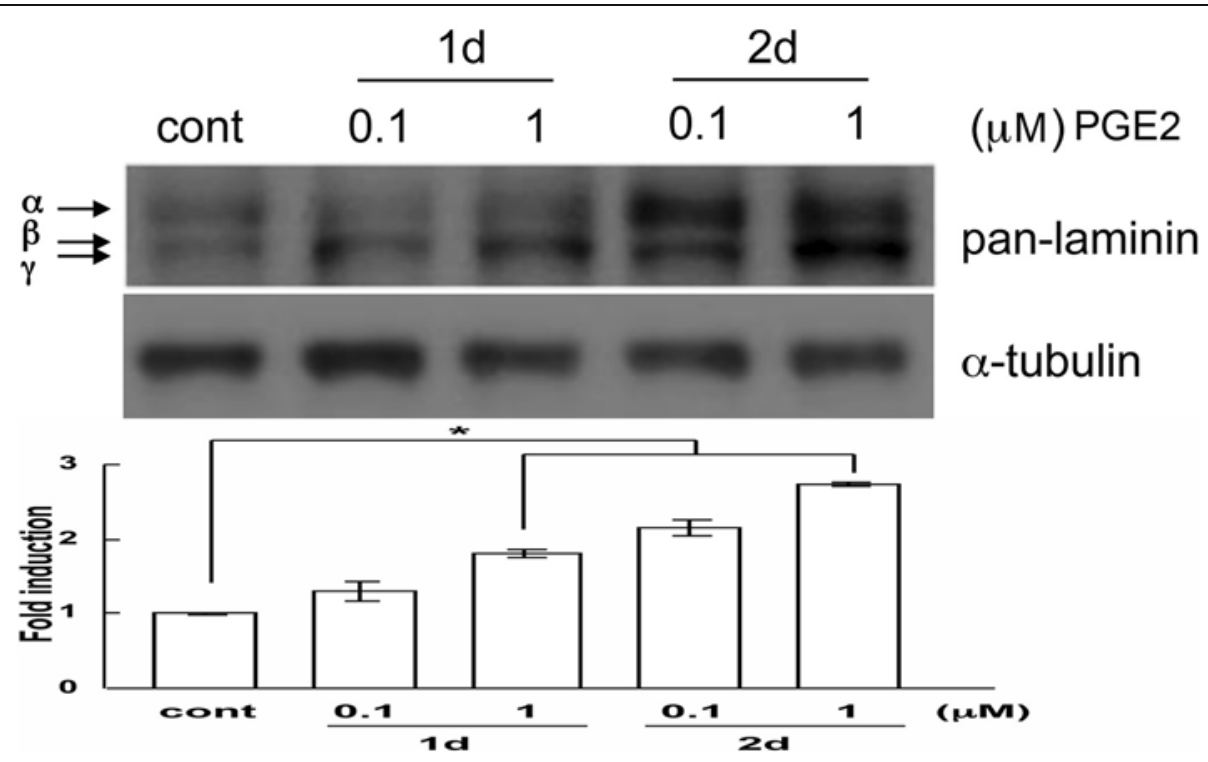

Figure 6 Laminin protein levels increase after treatment of endothelial cells with prostaglandin $E_{2}\left(\mathrm{PGE}_{2}\right)$. BMECs were treated with 0.1 and $1 \mu \mathrm{M} \mathrm{PGE}$ for 1 or 2 days. At the end of the incubation period the cells were lysed and subjected to western blot analysis to reveal laminin protein levels. $a$-Tubulin was used to normalize protein loading. Data are representative of three experiments. The $a, \beta$ and $\gamma$ subunits are indicated by arrows. ${ }^{*} P<0.01$ compared to control.

regulation of cytokine production in T cells [64]. $\mathrm{PGE}_{2}$ has the most known receptors with EP subtypes characterized as EP1 to EP4. Depending on the model of CNS injury, different EP receptors mediate the cellular signals. In a model of pulmonary emphysema angiogenesis was mediated by an EP2 agonist [66], whereas bone marrow cells expressing EP3 receptor enhanced angiogenesis during chronic inflammatory conditions [67]. In Lewis lung carcinoma the proangiogenic microenvironment was regulated via COX-2/EP3 or EP4 signaling [56]. In our study the effects of COX-2 on laminin expression were mediated through EP3 receptors. Our results suggest that although ECM changes are associated with the general acute inflammatory processes after MCAO, they may result from specific signaling changes. This latter hypothesis is supported by the fact that not all EP antagonists affect laminin expression, yet all affect other marker expression.

The observation that eventually laminin expression was recovered in COX-2-deficient animals at 2 days (data not shown) suggests that COX-2 deficiency delays the upregulation of the ECM protein laminin, potentially due to the release of different prostaglandins at early and late inflammatory stages and/or neuronal recovery during ischemic injury.

If the initial response of the ischemic tissue is an effort to promote neoangiogenesis to re-establish the blood flow [68,69], our data suggest that the early inflammatory reactions may be aiding such a process. Our results also point to molecular components critical for increased vascularization, suggesting that inhibition of molecules, such as EP3, may not be beneficial for stroke outcome.

\section{Conclusions}

Our study shows that following MCAO a transient upregulation of proteins of the ECM is observed, primarily of proteins associated with the endothelial cells of the CNS blood vessels. The presence of COX-2 and the pathway it initiates are important for this upregulation. Although we do not currently know why this ECM protein changes occur, we speculate that they constitute an early endogenous proangiogenic attempt from the tissue to re-establish oxygenation of the surrounding tissue.

\section{Additional files}

Additional file 1: Figure S1. Leukocyte infiltration during middle cerebral artery occlusion (MCAO). Sections at the indicated times after MCAO were stained with anti-CD45 antibody to visualize the timing of the infiltration of leukocytes into the central nervous system (CNS) parenchyma following MCAO.

Additional file 2: Figure S2. Vascular epithelial growth factor (VEGF) expression following middle cerebral artery occlusion (MCAO). VEGF protein expression was analyzed in 6 and $12 \mathrm{~h}$ extracts from ipsilateral sides after MCAO and was compared to levels on the contralateral side. a-Tubulin was used to normalize protein loading. ${ }^{*} P<0.01$ compared to control.

\section{Competing interests}

The authors declare no competing interests. 


\section{Acknowledgements}

We thank Drs Feng and van Nostrand for helping us with the MCAO models, and Dr Colognato's lab for advice. This study was supported by AHAEIA0540107N and R01NS42168 (SET).

\section{Authors' contributions}

KJ carried out the experiments described, analyzed data and drafted the manuscript. SET initiated and designed the study, analyzed data, and critically reviewed the manuscript. Both authors read and approved the final manuscript.

Received: 11 April 2012 Accepted: 3 July 2012

Published: 3 July 2012

\section{References}

1. Dirnagl U, ladecola C, Moskowitz M: Pathobiology of ischemic stroke: an integrated view. Trends Neurosci 1999, 22:391-397.

2. Wang $Q$, Tang $X$, Yenari $M$ : The inflammatory response in stroke. J Neuroimmunol 2007, 184:53-68.

3. Feng L, Sun W, Xia Y, Tang W, Chanmugam P, Soyoola E, Wilson C, Hwang D: Cloning two isoforms of rat cyclooxygenase: differential regulation of their expression. Arch Biochem Biophys 1993, 307:361-368.

4. Planas A, Soriano M, Rodriguez-Farre E, Ferrer I: Induction of cyclooxygenase- 2 mRNA and protein following transient focal ischemia in the rat brain. Neurosci Lett 1995, 200:187-190.

5. Herschman H: Prostaglandin synthase 2. Biochim Biophys Acta 1999, 1299:125-140.

6. Kawano Y, Nakamura S, Fukuda J, Miyakawa I: Synergistic effect of interleukin-1alpha and ceramide analogue on production of prostaglandin E2 and F2alpha by endometrial stromal cells. Am J Reprod Immunol 2001, 46:393-398.

7. Gilroy D, Colville-Nash P, Willis D, Chivers J, Paul-Clark M, Willoughby D: Inducible cyclooxygenase may have anti-inflammatory properties. Nat Med 1999, 5:698-701.

8. Graham S, Hickey R: Cyclooxygenases in central nervous system diseases: a special role for cyclooxygenase 2 in neuronal cell death. Arch Neurol 2003, 60:628-630

9. Vancheri C, Mastruzzo C, Sortino M, Crimi N: The lung as a privileged site for the beneficial actions of PGE2. Trends Immunol 2004, 25:40-46.

10. Yang M, Ji K, Jeon S, Jin B, Kim S, Jou I, Joe E: Interleukin-13 enhances cyclooxygenase-2 expression in activated rat brain microglia: implications for death of activated microglia. J Immuno/ 2006, 177:1323-1329.

11. Harizi H, Juzan M, Pitard V, Moreau J, Gualde N: Cyclooxygenase-2-issued prostaglandin e(2) enhances the production of endogenous IL-10, which down-regulates dendritic cell functions. J Immunol 2002, 168:2255-2263.

12. Eljaschewitsch E, Witting A, Mawrin C, Lee T, Schmidt P, Wolf S, Hoertnagl H, Raine C, Schneider-Stock R, Nitsch R, Ullrich O: The endocannabinoid anandamide protects neurons during CNS inflammation by induction of MKP-1 in microglial cells. Neuron 2006, 49:67-79.

13. Nagayama M, Niwa K, Nagayama T, Ross M, ladecola C: The cyclooxygenase-2 inhibitor NS-398 ameliorates ischemic brain injury in wild-type mice but not in mice with deletion of the inducible nitric oxide synthase gene. J Cereb Blood Flow Metab 1999, 19:1213-1219.

14. Kawano T, Anrather J, Zhou P, Park L, Wang G, Frys K, Kunz A, Cho S, Orio $M$, ladecola C: Prostaglandin E2 EP1 receptors: downstream effectors of COX-2 neurotoxicity. Nat Med 2006, 12:225-229.

15. Liang X, Wu L, Wang Q, Hand T, Bilak M, McCullough L, Andreasson K: Function of COX-2 and prostaglandins in neurological disease. $J \mathrm{Mol}$ Neurosci 2007, 33

16. Rauch U: Extracellular matrix components associated with remodeling processes in brain. Cell Mol Life Sci 2004, 61:2031-2045

17. Bellail A, Hunter S, Brat D, Tan C, Van Meir E: Microregional extracellular matrix heterogeneity in brain modulates glioma cell invasion. Int $J$ Biochem Cell Biol 2004, 36:1046-1069.

18. Jones J, Lane K, Hopkinson S, Lecuona E, Geiger R, Dean D, Correa-Meyer E, Gonzales M, Campbell K, Sznajder J, Budinger S: Laminin-6 assembles into multimolecular fibrillar complexes with perlecan and participates in mechanical-signal transduction via a dystroglycan-dependent, integrinindependent mechanism. J Cell Sci 2005, 118:2557-2566.
19. Yamaguchi Y: Lecticans: organizers of the brain extracellular matrix. Cell Mol Life Sci 2000, 57:276-289.

20. Giamanco K, Morawski M, Matthews R: Perineuronal net formation and structure in aggrecan knockout mice. Neuroscience 2010 170:1314-1327.

21. Yu Y, Cristofanilli M, Valiveti A, Ma L, Yoo M, Morellini F, Schachner M: The extracellular matrix glycoprotein tenascin-C promotes locomotor recovery after spinal cord injury in adult zebrafish. Neuroscience 2011 183:238-250.

22. Zacharias $U$, Rauch $U$ : Competition and cooperation between tenascin- $R$, lecticans and contactin 1 regulate neurite growth and morphology. J Cell Sci 2006, 119:3456-3466.

23. Rigato F, Garwood J, Calco V, Heck N, Faivre-Sarrailh C, Faissner A: Tenascin-C promotes neurite outgrowth of embryonic hippocampal neurons through the alternatively spliced fibronectin type III BD domains via activation of the cell adhesion molecule F3/contactin. J Neurosci 2002, 22:6596-6609.

24. Fukuda S, Fini C, Mabuchi T, Koziol J, Eggleston LJ, del Zoppo G: Focal cerebral ischemia induces active proteases that degrade microvascular matrix. Stroke 2004, 35:998-1004.

25. Baeten $\mathrm{K}$, Akassoglou K: Extracellular matrix and matrix receptors in blood-brain barrier formation and stroke. Dev Neurobiol 2011, 71:1018-1039.

26. Nagel S, Sandy J, Meyding-Lamade U, Schwark C, Bartsch J, Wagner S: Focal cerebral ischemia induces changes in both MMP-13 and aggrecan around individual neurons. Brain Res 2005, 1056:43-50.

27. Hobohm C, Günther A, Grosche J, Rossner S, Schneider D, Brückner G: Decomposition and long-lasting downregulation of extracellular matrix in perineuronal nets induced by focal cerebral ischemia in rats. J Neurosci Res 2005, 80:539-548.

28. Smirkin A, Matsumoto $\mathrm{H}$, Takahashi $\mathrm{H}$, Inoue A, Tagawa M, Ohue $\mathrm{S}$, Watanabe H, Yano H, Kumon Y, Ohnishi T, Tanaka J: Iba1(+)/NG2(+) macrophage-like cells expressing a variety of neuroprotective factors ameliorate ischemic damage of the brain. J Cereb Blood Flow Metab 2010, 30:603-615.

29. Han Q, Li B, Feng H, Xiao Z, Chen B, Zhao Y, Huang J, Dai J: The promotion of cerebral ischemia recovery in rats by laminin-binding BDNF. Biomaterials 2011, 32:5077-5085.

30. Ellison J, Velier J, Spera P, Jonak Z, Wang X, Barone F, Feuerstein G: Osteopontin and its integrin receptor alpha(v)beta3 are upregulated during formation of the glial scar after focal stroke. Stroke 1998 29:1698-1706

31. Meller R, Stevens S, Minami M, Cameron J, King S, Rosenzweig H, Doyle K, Lessov N, Simon R, Stenzel-Poore M: Neuroprotection by osteopontin in stroke. J Cereb Blood Flow Metab 2005, 25:217-225.

32. Engel J, Furthmayr H: Electron microscopy and other physical methods for the characterization of extracellular matrix components: laminin, fibronectin, collagen IV, collagen VI, and proteoglycans. Methods Enzymol 1987, 145:3-78.

33. Indyk J, Chen Z, Tsirka S, Strickland S: Laminin chain expression suggests that laminin-10 is a major isoform in the mouse hippocampus and is degraded by the tissue plasminogen activator/plasmin protease cascade during excitotoxic injury. Neuroscience 2003, 116:359-371.

34. Durbeej M: Laminins. Cell Tissue Res 2010, 339:259-268.

35. Sixt M, Engelhardt $B$, Pausch F, Hallmann $R$, Wendler $O$, Sorokin L: Endothelial cell laminin isoforms, laminins 8 and 10, play decisive roles in $T$ cell recruitment across the blood-brain barrier in experimental autoimmune encephalomyelitis. J Cell Biol 2001, 153:933-946.

36. Hagg T, Portera-Cailliau C, Jucker M, Engvall E: Laminins of the adult mammalian CNS; laminin-alpha2 (merosin M-) chain immunoreactivity is associated with neuronal processes. Brain Res 1997, 764:17-27.

37. Li S, Overman J, Katsman D, Kozlov S, Donnelly C, Twiss J, Giger R, Coppola G, Geschwind D, Carmichael S: An age-related sprouting transcriptome provides molecular control of axonal sprouting after stroke. Nat Neurosci 2010, 13:1496-1504

38. Wagner $\mathrm{S}$, Gardner $\mathrm{H}$ : Modes of regulation of laminin-5 production by rat astrocytes. Neurosci Lett 2000, 284:105-108.

39. Villanova M, Malandrini A, Sabatelli P, Sewry CA, Toti P, Torelli S, Six J, Scarfó G, Palma L, Muntoni F, Squarzoni S, Tosi P, Maraldi NM, Guazzi GC: Localization of laminin alpha 2 chain in normal human central nervous system: an immunofluorescence and ultrastructural study. Acta Neuropathol 1997, 94:567-571.

40. Jucker M, Bialobok P, Kleinman H, Walker L, Hagg T, Ingram D: Laminin-like and laminin-binding protein-like immunoreactive astrocytes in rat hippocampus after transient ischemia. Antibody to laminin-binding 
protein is a sensitive marker of neural injury and degeneration. Ann NY Acad Sci 1993, 679:245-252.

41. Szabo A, Kalman M: Disappearance of the post-lesional laminin immunopositivity of brain vessels is parallel with the formation of gliovascular junctions and common basal lamina. A double-labelling immunohistochemical study. Neuropathol Appl Neurobiol 2004, 30:169-177.

42. Callahan M, Williams K, Kivisakk P, Pearce D, Stins M, Ransohoff R: CXCR3 marks CD4+ memory $T$ lymphocytes that are competent to migrate across a human brain microvascular endothelial cell layer. J Neuroimmunol 2004, 153:150-157.

43. Yao Y, Tsirka S: Truncation of monocyte chemoattractant protein 1 by plasmin promotes blood-brain barrier disruption. J Cell Sci 2011, 124:1486-1495.

44. Seidel S, Garvalov BK, Wirta V, von Stechow L, Schänzer A, Meletis K, Wolter M, Sommerlad D, Henze AT, Nistér M, Reifenberger G, Lundeberg J, Frisén J, Acker T: A hypoxic niche regulates glioblastoma stem cells through hypoxia inducible factor 2 alpha. Brain 2010, 133:983-995.

45. Galanakis DK, Henschen-Edman A, Weisel J, Spitzer S: Antifibrinogen IgG, fibrinogen, and Clq complexes circulating in a hypodysfibrinogenemic proband. Isolation, stoichiometry, and partial characterization. Ann N Y Acad Sci 2001, 936:611-616.

46. Iadecola C, Niwa K, Nogawa S, Zhao X, Nagayama M, Araki E, Morham S, Ross M: Reduced susceptibility to ischemic brain injury and $N$-methyl-D aspartate-mediated neurotoxicity in cyclooxygenase-2-deficient mice. Proc Natl Acad Sci USA 2001, 98:1294-1299.

47. Yanni S, McCollum G, Penn J: Genetic deletion of COX-2 diminishes VEGF production in mouse retinal Müller cells. Exp Eye Res 2010, 91:34-41.

48. Hagg T, Muir D, Engvall E, Varon S, Manthorpe M: Laminin-like antigen in rat CNS neurons: distribution and changes upon brain injury and nerve growth factor treatment. Neuron 1989, 3:721-732.

49. Filiano A, Bailey C, Tucholski J, Gundemir S, Johnson G: Transglutaminase 2 protects against ischemic insult, interacts with HIF1beta, and attenuates HIF1 signaling. FASEB J 2008, 22:2662-2675.

50. Ikeda-Matsuo Y, Tanji H, Ota A, Hirayama Y, Uematsu S, Akira S, Sasaki Y: Microsomal prostaglandin E synthase-1 contributes to ischaemic excitotoxicity through prostaglandin E2 EP3 receptors. Br J Pharmacol 2010, 160:847-859.

51. Manthorpe M, Engvall E, Ruoslahti E, Longo F, Davis G, Varon S: Laminin promotes neuritic regeneration from cultured peripheral and central neurons. J Cell Biol 1983, 97:1882-1890

52. Anton E, Sandrock A, Matthew W: Merosin promotes neurite growth and Schwann cell migration in vitro and nerve regeneration in vivo: evidence using an antibody to merosin. Dev Biol 1994, 164:133-146.

53. Liesi P: Laminin-immunoreactive glia distinguish regenerative adult CNS systems from non-regenerative ones. EMBO J 1985, 4:2505-2511.

54. Malinda K, Wysocki A, Koblinski J, Kleinman H, Ponce M: Angiogenic laminin-derived peptides stimulate wound healing. Int J Biochem Cell Biol 2008, 40:2771-2780.

55. Nguyen B, Ryan M, Gil S, Carter WG: Deposition of laminin 5 in epidermal wounds regulates integrin signaling and adhesion. Curr Opin Cell Biol 2000, 12:554-562.

56. Katoh H, Hosono K, Ito Y, Suzuki T, Ogawa Y, Kubo H, Kamata H, Mishima T, Tamaki $H$, Sakagami $H$, Sugimoto $Y$, Narumiya S, Watanabe M, Majima M: COX-2 and prostaglandin EP3/EP4 signaling regulate the tumor stromal proangiogenic microenvironment via CXCL12-CXCR4 chemokine systems. Am J Pathol 2010, 176:1469-1483.

57. Urushibata S, Hozumi K, Ishikawa M, Katagiri F, Kikkawa Y, Nomizu M: Identification of biologically active sequences in the laminin alpha2 chain G domain. Arch Biochem Biophys 2010, 497:43-54.

58. Shibuya S, Wakayama Y, Inoue M, Kojima H, Oniki H: Merosin (laminin-2) localization in basal lamina of normal skeletal muscle fibers and changes in plasma membrane of merosin-deficient skeletal muscle fibers. Med Electron Microsc 2003, 36:213-220.

59. Wagner S, Tagaya M, Koziol J, Quaranta V, del Zoppo G: Rapid disruption of astrocyte interaction with the extracellular matrix mediated by integrin alpha6 beta4 during focal cerebral ischemia/reperfusion. Stroke 1997 , 28:858-865.

60. Chen Z, Yu H, Yu W, Pawlak R, Strickland S: Proteolytic fragments of laminin promote excitotoxic neurodegeneration by up-regulation of the KA1 subunit of the kainate receptor. J Cell Biol 2008, 183:1299-1313.
61. Skrzypiec A, Maiya R, Chen Z, Pawlak R, Strickland S: Plasmin-mediated degradation of laminin gamma-1 is critical for ethanol-induced neurodegeneration. Biol Psych 2009, 66:785-794.

62. Narumiya S, FitzGerald G: Genetic and pharmacological analysis of prostanoid receptor function. J Clin Invest 2001, 108:25-30.

63. Hata A, Breyer R: Pharmacology and signaling of prostaglandin receptors: multiple roles in inflammation and immune modulation. Pharmacol Ther 2004, 103:147-166.

64. Harris S, Padilla J, Koumas L, Ray D, Phipps R: Prostaglandins as modulators of immunity. Trends Immunol 2002, 23:144-150.

65. Legler D, Bruckner M, Uetz-von Allmen E, Krause P: Prostaglandin E2 at new glance: novel insights in functional diversity offer therapeutic chances. Int J Biochem Cell Biol 2010, 42:198-201.

66. Tsuji T, Aoshiba K, Yokohori N, Nagai A: A systemically administered EP2 receptor agonist stimulates pulmonary angiogenesis in a murine model of emphysema. Prostaglandins Other Lipid Mediat 2009, 90:85-88.

67. Ueno T, Suzuki T, Oikawa A, Hosono K, Kosaka Y, Amano H: Recruited bone marrow cells expressing the EP3 prostaglandin E receptor subtype enhance angiogenesis during chronic inflammation. Biomed Pharmacother 2010, 64:93-100.

68. Jiang W, Zhang S, Zhu H, Hou J: Effect of 8-O-acetyl Shanzhiside methylester increases angiogenesis and improves functional recovery after stroke. Basic Clin Pharmacol Toxicol 2011, 108:21-27.

69. Seevinck P, Deddens L, Dijkhuizen R: Magnetic resonance imaging of brain angiogenesis after stroke. Angiogenesis 2010, 13:101-111.

doi:10.1186/1742-2094-9-159

Cite this article as: Ji and Tsirka: Inflammation modulates expression of laminin in the central nervous system following ischemic injury. Journal of Neuroinflammation 2012 9:159.

\section{Submit your next manuscript to BioMed Central and take full advantage of:}

- Convenient online submission

- Thorough peer review

- No space constraints or color figure charges

- Immediate publication on acceptance

- Inclusion in PubMed, CAS, Scopus and Google Scholar

- Research which is freely available for redistribution 